\title{
INFANCIA Y TELEVISIÓN: EL MARCO NORMATIVO COLOMBIANO (1998-2012)
}

\section{CHILHOOD AND TELEVISION: THE COLOMBIAN NORMATIVE FRAME 1998-2012}

\author{
Mg. Yamile Sandoval Romero ${ }^{1}$ \\ yamilesandoval@usc.edu.co \\ Dr. Ignacio Aguaded ${ }^{2}$ \\ ignacio@aguaded.es \\ Jacqueline Sánchez Carrero ${ }^{3}$ \\ jacqueline.sanchez.pi@uhu.es
}

${ }^{1}$ Universidad Santiago de Cali. Facultad de Comunicación y Publicidad. Departamento de Comunicación. Calle 5ta. Carrera 62 Campus Pampa Linda, Cali (Colombia)

${ }^{2}$ Universidad de Huelva. Facultad de Educación.

Departamento de Educación. Campus El Carmen. 21071 Huelva (España)

${ }^{3}$ Universidad Internacional de Andalucía. Master Oficial Interuniversitario de

Comunicación y Educación Audiovisual de la Universidad de Huelva. Calle Eduardo

Cano, 4, 2. J. Sevilla (España)

Expone el resultado del análisis de la normatividad emitida por la Comisión Nacional de Televisión (1998-2012) en Colombia, identificando aspectos privilegiados en la relación televisión e infancia, aportando al mundo de la televisión. Desde un enfoque mixto combina el análisis de contenido con una matriz de análisis, clasificando los aspectos en los que se han centrado los acuerdos emitidos por este organismo. Como evidencia, interés marcado por regular el tratamiento audiovisual de los contenidos, seguido por determinar la franja horaria de emisión; vacíos en la existencia de normativa en el tiempo y la desaparición del fomento a la producción nacional.

Palabras clave: Televisión, infancia, comunicación y educación.

The article presents the results of the analysis of the regulations issued by the National Commission for Television (1998-2012) in Colombia, identifying privileged aspects in the relationship television and children, in order to contribute to the characterization of children's television. It follows a mixed research method that combines content analysis with an analysis matrix and classifies relevant aspects of the agreements delivered by the commission. These aspects are: a marked interest to regulate the treatment towards audiovisual content followed by the interest in determining specific broadcasting hours, regulation gaps in time and finally the disappearance of promotion of national TV.

Keywords: Television, childhood, communication and education.

- 195 -

Píxel-Bit. Revista de Medios y Educación. No 47 Julio 2015. ISSN: 1133-8482. e-ISSN: 2171-7966. doi: http://dx.doi.org/10.12795/pixelbit.2015.i47.13 


\section{Introducción.}

Bajo el gobierno militar del General Rojas Pinilla el 13 de junio de 1954 se inaugura la televisión en Colombia y al igual que en la mayoría de los países Latinoamericanos, su llegada está vinculada como lo anota Fuenzalida (2000), a la ideología política del momento y bajo el auspicio Estatal.

Vizcaíno (2005, p. 133) divide la historia de la televisión en Colombia en tres fases: «la primera de estatización sin intervención directa de partidos políticos, durante la administración Rojas Pinilla; la segunda de estatización con intervención de partidos políticos; y la tercera de estatización con partidos políticos y con representaciones de la sociedad civil» y cita el Decreto 3363 de 1954, como el documento jurídico que le da origen a la sección de televisión, adscrita a la Oficina de Información y Propaganda del Estado (ODIPE), hasta que en enero de 1955, se crea la Televisora Nacional como entidad autónoma. Posterior a esto, en 1963 y después de elevar su autonomía y especificidad, se crea el Instituto Nacional de Radio y Televisión (INRAVISIÓN), adscrito al mismo Ministerio de Comunicaciones.

En términos generales, el sistema mixto de operación en el que el Estado era dueño de las frecuencias y operadores privados actuaban como productores y comercializadores de contenidos para televisión se extendió por 40 años. En 1997 la Comisión Nacional de Televisión (CNTV) otorga las licencias a los canales RCN y Caracol para operar como canales privados, concentrándose la operación en los dos grupos económicos y haciendo que paulatinamente las empresas productoras de televisión se fusionaran o desaparecieran en este nuevo panorama comercial.
En este escenario, se pueden identificar normas que rigen en especial la operación del espectro electromagnético. Sin embargo es hasta 1991, con la reforma de la constitución política cuando se propicia el espacio para la regulación específica de contenidos al crear la CNTV mediante el artículo 76, que le da origen y el 77 que le da poder frente a la dirección de la política en materia de televisión que determine la ley. Antes de la expedición de la Ley 182 de 1995 la cual conforma oficialmente la CNTV, actuaba como órgano de dirección y administración el Consejo Nacional de Televisión, creado por la Ley 42 de 1985 y ratificado mediante Ley 14 de 1991.

Después de un largo debate político en julio de 2011 la ley faculta al gobierno nacional para liquidar la CNTV y mediante la Ley 1507 del 2012, se crea la Autoridad Nacional de Televisión (ANTV), como una agencia nacional estatal de naturaleza especial.

La Ley 182 de 1995, consignaba de manera expresa 16 funciones para la CNTV, dentro de las cuales, una está asociada directamente con el público infantil:

n) Sancionar a los operadores, concesionarios de espacios de televisión y contratistas de televisión nacional cuando violen las disposiciones constitucionales y legales que amparan específicamente los derechos de la familia y de los niños. De acuerdo con la reglamentación que para tal efecto expida la CNTV en el término de los seis meses siguientes a la vigencia de la presente ley, los infractores se harán acreedores de las sanciones de amonestación, suspensión temporal del servicio hasta por cinco meses o caducidad o revocatoria de la concesión o licencia, según la gravedad de la infracción, la reincidencia. En todo caso, se 
respetarán las normas establecidas en la ley sobre el debido proceso (Artículo 5).

En el artículo 3 de la Ley 1507 de 2012, para el nuevo organismo, se sostienen 11 de las 16 funciones y se reformula la asociada a la infancia, unificando de manera general el ámbito de acción a los prestadores del servicio público y eliminando las posibles sanciones, especificando en su apartado e) «Sancionar cuando haya lugar a quienes violen con la prestación del servicio público de televisión, las disposiciones constitucionales y legales que amparan específicamente los derechos de la familia y de los niños».

Bajo este marco institucional, se han desarrollado las diferentes políticas y estrategias jurídicas asociadas a la televisión y la audiencia infantil en Colombia, desde el momento mismo en que se inaugura el servicio público de televisión.

\subsection{Infancia, medios y Estado.}

De acuerdo con el documento Política Pública por la Primera Infancia (CPI) (2006), los derechos de los niños y niñas en el Estado colombiano, se elevan al rango constitucional mediante el artículo 44 de la Constitución política del año 1991, que enfatiza en considerarlos sujetos de derechos, recogiendo en gran medida lo consagrado en la Convención Internacional sobre Derechos del Niño, Ley 12 de 1991, la cual introduce un cambio en la concepción social de la infancia: «los niños deben ser reconocidos como sujetos sociales y como ciudadanos con derechos en contextos democráticos» (p. 13), en el artículo 13, reconoce la libertad de expresión del niño, derecho que incluye la libertad de buscar, recibir y difundir informaciones e ideas de todo tipo, sin consideración de fronteras, ya sea oralmente, por escrito o impresas, en forma artística o por cualquier otro medio elegido por el niño.

Asimismo, el inciso a), del artículo 17, consagra que los Estados Partes alentarán a los medios de comunicación a difundir información y materiales de interés social y cultural para el niño, de conformidad con el espíritu del artículo 29, que configura el carácter propio de la educación del niño. Seguidamente, en el inciso d), insta a proteger las necesidades lingüísticas especiales y en el siguiente, a preservar la integridad al elaborar directrices que lo protejan contra toda información y material perjudicial para su bienestar.

La conciencia sobre el cuidado y la protección de la infancia, se remonta al año 1968, con la Ley 75, que daba origen al actual Instituto de Bienestar Familiar (ICBF). Después y de manera gradual, las leyes han estado orientadas a fortalecer la política de protección integral haciendo énfasis en diferentes aspectos. Para 1974 y 1976, con la Ley 27 y el decreto 088 respectivamente, se afianzan los programas de creación de espacios educativos infantiles, tal como se relata en los antecedentes de La Política Pública por la Primera Infancia.

De manera recurrente, el tema de la situación de salud, los procesos de socialización y los niveles de educación adecuados para el infante, han sido objeto de normatividad durante los últimos 40 años. La ampliación de la edad de cobertura y el concepto de desarrollo integral, también han estado presentes en las estrategias incluidas en los diferentes planes y programas (19821986; 1986-1990).

Los medios de comunicación, aparecen para el año 1995, con el documento emitido por el Consejo Nacional de Política 
Económica y Social (CONPES) 2787, como espacios de divulgación de estrategias para la socialización y apropiación de los derechos y deberes de los niños y los deberes y valores de la familia colombiana, pero bajo la responsabilidad del ICBF.

Para el año 2006 son evidentes las acciones encaminadas por entidades de los diferentes ámbitos de la sociedad para reconocer oficialmente a los medios de comunicación como actores importantes en la relación infancia y desarrollo. En el documento Colombia por la Primera Infancia (2006), en el que se materializa la política pública por los niños y niñas, desde la gestación hasta los 6 años, se admite textualmente que «la relación entre Familia y Estado se ha ido modificando, en tanto que aparecen múltiples instancias mediadoras como la escuela, los programas de bienestar social, las instituciones recreativas y de salud, y los medios de comunicación» (p. 36).

Por su parte el Plan Decenal de Educación 2006-2016 (PDE), dedica el capítulo II Educación en y para la paz, la convivencia y la ciudadanía, a destacar los medios de comunicación y su relación con la educación en la infancia. De esta manera, los medios de comunicación ocupan socialmente el papel que siempre han tenido pero que oficialmente no había sido reconocido. Este paso formal, permite que a partir de este momento, se tracen políticas y planes tendientes a la operativización de las normas existentes hasta ese momento.

El que el año 2006 marque un cambio cualitativo y cuantitativo con relación con el reconocimiento de los medios de comunicación en los escenarios educativos y normativos del país, sin lugar a dudas es resultado directo de la promulgación del Código de Infancia y Adolescencia (CIA)
(2006, p.1), sancionado bajo la Ley $1098 \mathrm{de}$ noviembre de 2006, en un ambiente de reflexión frente al papel del Estado y la sociedad en la protección de los derechos de los niños, niñas y adolescentes. El objetivo principal, del CIA consiste en «garantizar a los niños, a las niñas y a los adolescentes su pleno y armonioso desarrollo para que crezcan en el seno de la familia y de la comunidad, en un ambiente de felicidad, amor y comprensión. Prevalecerá el reconocimiento a la igualdad y la dignidad humana, sin discriminación humana».

Para analizar la transcendencia del mismo, es necesario remontarse al Código del Menor, documento que precede al código de infancia y adolescencia. Reglamentado mediante el decreto 2737 de 1989, reconoce la responsabilidad de los medios de comunicación relacionados con los derechos del menor, incluyendo un título completo sobre la Responsabilidad de los Medios de Comunicación, sentando las bases para lo que se desarrollaría con detalle en el código de infancia y adolescencia 17 años después.

El objetivo con el articulado es proteger la integridad, intimidad y moralidad del menor, para lo cual regula la forma como se presentan públicamente los menores con el fin de respetar su integridad física, psicológica y moral (artículos, 25 y 300 al 303) y mediante el artículo 304, se obliga al Consejo Nacional de Televisión o al organismo que haga sus veces, a informar la clasificación del contenido con relación a la presencia de menores frente a la pantalla.

La primera diferencia que introduce el Código de Infancia y Adolescencia (2006, p. 3 ), radica en la diferenciación de la categoría de niño, que para la Ley 12 de 1991, era «todo ser humano menor de dieciocho años de edad, salvo que, en virtud de la ley que le sea 
aplicable, haya alcanzado antes la mayoría de edad». En el CIA el artículo 3 determina como sujetos de derechos, a todas las personas menores de 18 años y aclara que «se entiende por niño o niña las personas entre los 0 y 12 años, y por adolescentes las personas entre los 12 y 18 años de edad» (p. 1). Más adelante en el artículo 29, segmenta la infancia definiendo la etapa de primera infancia como aquella que «comprende la franja poblacional que va de los cero (0) a los seis (6) años de edad» (p.14); reafirma el derecho a informarse de los menores y confiere responsabilidades especiales de los medios de comunicación:

Los medios de comunicación, en el ejercicio de su autonomía y demás derechos, deberán:

1. Promover, mediante la difusión de información, los derechos y libertades de los niños, las niñas y los adolescentes, así como su bienestar social y su salud física y mental.

2. El respeto por la libertad de expresión y el derecho a la información de los niños, las niñas y los adolescentes.

3. Adoptar políticas para la difusión de información sobre niños, niñas y adolescentes en las cuales se tenga presente el carácter prevalente de sus derechos.

4. Promover la divulgación de información que permita la localización de los padres o personas responsables de niños, niñas o adolescentes cuando por cualquier causa se encuentren separados de ellos, se hayan extraviado o sean solicitados por las autoridades competentes.

5. Abstenerse de transmitir mensajes discriminatorios contra la infancia y la adolescencia.

6. Abstenerse de realizar transmisiones o publicaciones que atenten contra la integridad moral, psíquica o física de los menores, que inciten a la violencia, que hagan apología de hechos delictivos o contravenciones, o que contengan descripciones morbosas o pornográficas.

7. Abstenerse de transmitir por televisión publicidad de cigarrillos y alcohol en horarios catalogados como franja infantil por el organismo competente.

8. Abstenerse de entrevistar, dar el nombre, divulgar datos que identifiquen o que puedan conducir a la identificación de niños, niñas y adolescentes que hayan sido víctimas, autores o testigos de hechos delictivos, salvo cuando sea necesario para garantizar el derecho a establecer la identidad del niño o adolescente víctima del delito, o la de su familia si esta fuere desconocida. En cualquier otra circunstancia, será necesaria la autorización de los padres o, en su defecto, del Instituto Colombiano de Bienestar Familiar.

Parágrafo. Los medios de comunicación serán responsables por la violación de las disposiciones previstas en este artículo. El Instituto Colombiano de Bienestar Familiar podrá hacerse parte en los procesos que por tales violaciones se adelanten contra los medios.

Desde el año 2006 momento en que se promulga la ley, se han desarrollado iniciativas que permiten el cumplimiento en algunos de los casos previstos por el código. Sin embargo, para estar cumpliendo 60 años de la inauguración del servicio público de televisión en Colombia, y 87 desde que se emitieron las primeras señales de televisión, parece un poco tardío el reconocimiento de la relación entre medios de comunicación en infancia, más aún cuando gracias a la explosión de investigaciones académicas, estaban comprobados sus efectos casi desde el momento mismo de sus primeras emisiones. 
Las leyes en las que se fundamenta la reglamentación emanada desde la CNTV, además del articulado de la Constitución política que le da origen a la entidad, son principalmente la 182 de 1995, en la que se consagran las funciones de la misma, y la 336 de 1996. Adicionalmente, se encuentran relacionadas la 1098 del 2006, por la que se expide el Código de Infancia y Adolescencia y específicamente en el tema de acceso, la 361 de 1997; 982 de 2006 y 1346 de 2009.

Sin embargo, es la figura del acuerdo, la que concreta la reglamentación y permite determinar qué aspectos de la ley fueron privilegiados al momento de realizar el seguimiento y control a la relación infancia y televisión en Colombia.

\section{Metodología.}

En cumplimiento de sus funciones, la CNTV reglamenta las disposiciones generales de la ley, a través de acuerdos que serán materia de análisis en el presente apartado. Para el análisis que se expone, se utilizó la investigación documental, seleccionando de la página web de la ANTV, los documentos jurídicos que contuvieran algún tipo de normatividad relacionada con la televisión y la infancia. Los 10 acuerdos encontrados, son analizados desde un enfoque cualitativo inicial, sustentado en la necesidad de ajustarnos a los objetivos perseguidos tal como lo cita Cáceres (2003, p. 54) «la investigación cualitativa ofrece de este modo la posibilidad de asumir ponderaciones y regulaciones científicas propias de una perspectiva en uso, que genera conocimiento ajustado a los objetivos de base de dichas orientaciones». Siguiendo al mismo autor se aplica la técnica análisis de contenido, entendida como la técnica que analiza el contenido manifiesto, muy cercano a lo que denomina Aronson (1994), citado por el mismo Cáceres (2003) como análisis temático, en este caso, agrupando los datos en conjuntos temáticos, denominados criterios, para elaborar un análisis de la relación que nos interesa.

Siguiendo los pasos propuestos por Bardin (1996, citado por Cáceres, 2003), en primer lugar se identifica el tema objeto de estudio, en este caso la normatividad existente para la relación televisión e infancia; en segundo lugar, se recolectan los instrumentos, se diseñan las guías de trabajo y se establecen los criterios, lo que permite identificar aspectos relevantes y agruparlos en 6 criterios, que se convierten en las categorías de análisis, fijando las reglas o códigos que se aplicarán durante el análisis, las cuales se explicitan en el Cuadro 1.

El tercer paso constituye la fijación de las unidades de análisis, en este caso compuestas por los artículos dentro de cada acuerdo que hacen referencia a la relación televisión e infancia, conocidos como ítems, de acuerdo con lo propuesto por Hernández citado por Cáceres (2003, p. 62) «la unidad total empleada por los productores de material simbólico», e incluirlos en los criterios determinados en el paso 2. En algunos casos, el mismo ítem reglamenta dos aspectos o más, por lo que se incluye en cada categoría a la que corresponda. De esta manera el paso cuarto de nuestro procedimiento, incluye en una matriz de análisis cuantitativo los ítems de acuerdo con cada categoría, para arrojar los resultados finales del análisis.

\section{Resultados.}

Comenzamos diciendo que el inciso $\mathrm{n}$ ), del artículo 5 de la Ley 182 de 1995, consignaba 
CÓDIGO FHPG (Franjas horarias y programación)

DEF INICIÓN Artículos que regulan los temas de franjas horarias en las que se incluya la audiencia infantil, o

COMPLETA que hablen del tipo o adecuación de la programación a dichas franjas

Se incluyen artículos con parágrafos que puntualicen, a pesar de que no existe en el cuerpo

EJEMPLO Acuerdo 7 de 1996 principal del mismo (Ejemplo: Acuerdo 010/1997, artículo 15, parágrafo 1)

Artículo $3^{\circ}$. Clasificación según el Tipo de Audiencia Habitual. Los espacios de televisión se clasifican según el tipo de audiencia habitual, cuyas características determinan la naturaleza y horario de la programación a emitir. Se establecen las siguientes franjas: infantil, familiar y adultos.

Artículo $16^{\circ}$. Contenido de la programación. El contenido de los programas y el tratamiento de su temática, deberá ajustarse a la franja de audiencia escogida para su emisión.

CÓDIGO AEHR (Advertencia edad mínima / hora de recepción)

DEFINICIÓN Artículos que regulan la necesidad de que los operadores de televisión adviertan sobre la edad

COMPLETA mínima para ver el contenido emitido y la hora de recepción apta para las audiencias infantiles. Se incluyen artículos con parágrafos que puntualicen, a pesar de que no existe en el cuerpo principal del mismo (Ejemplo: Acuerdo 010 de 1997, artículo 15, parágrafo 1)

EJEMPLO Acuerdo 017 de 1997

Artículo $2^{\circ}$. Aviso sobre el contenido de los programas. Cada vez que se inicie la transmisión de un programa en la franja familiar y de adultos, se le deberá avisar a la audiencia, tanto por vídeo como por audio, la edad mínima apta para presenciar el respectivo programa, si contiene violencia o escenas sexuales, y si por el contenido del programa a los menores se les recomiend a la compañía de padres o adultos

CÓDIGO CTA (contenido y tratamiento audiovisual)

DEF INICIÓN Artículos que regulan el tratamiento audiovisual y los temas que se deben tratar en los COMPLETA contenidos emitidos en la franja infantil.

EJEMPLO Acuerdo 017 de 1997

Artículo $4^{\circ}$. Tratamiento visual de la violencia. En las escenas de violencia que sean imprescindibles en los programas de televisión que se emitan en la franja infantil y familiar, no se podrán utilizar primeros planos sobre los hechos, ni entrar en descripciones morbosas, ni enfatizar, mediante repeticiones sucesivas, cámara lenta o cualquier otro efecto, en detalles innecesarios.

Artículo 23. Sexo en los comerciales. En la franja infantil no se presentarán anuncios comerciales o promocionales o avances de programas que incluyan escenas de sexo. En la franja familiar se podrán presentar, siempre y cuando el sexo esté implícito en la naturaleza del producto o servicio que se publicita. Los comerciales deberán respetar la clasificación de la franja de audiencia en que se vayan a transmitir.

\begin{tabular}{ll}
\hline CÓDIGO & PR (Producción de contenidos infantiles) \\
\hline DEF INICIÓN & Artículos que regulen la cantidad en horas u otra medida, de contenidos infantiles que deben ser \\
COMPLETA & emitidos por los operadores de televisión.
\end{tabular}

EJEMPLO Acuerdo 02 de 2011

Artículo 33. Obligaciones de programación. Cada operador de televisión abierta nacional, regional y local con ánimo de lucro deberá cumplir las siguientes obligaciones de programación: Programación infantil

Cada operador de televisión abierta deberá radiodifund ir un mínimo de horas trimestrales de programación infantil, teniendo en cuenta la definición consagrada en el artículo 25 del presente Acuerdo, en el horario comprendido entre las 07:00 y las 21:30 horas, de la siguiente manera: ...

CÓDIGO ACC (Acceso a los contenidos para el público infantil)

DEFINICIÓN Artículos que regulan el acceso de la población infantil con o sin discapacidad, a los contenidos COMPLETA aptos para ellos.

EJEMPLO Acuerdo 02 de 2012

Artículo 11. Obligaciones de los operadores y/o concesionarios. Dentro del porcentaje de programación que los concesionarios y/o operadores del servicio público de televisión están obligados a cumplir y manteniendo una proporcionalidad con respecto a los plazos para el incremento de los sistemas de acceso de que trata el artículo 10, deberán asegurar a la población sorda:

d) El acceso a programas infantiles, diseñados y realizados para satisfacer las necesidades de entretenimiento, educación o formación de niños entre 0 y 12 años, cuya narrativa y lenguaje responden al perfil de esa audiencia, conforme lo previsto en el numeral 1 del artículo 33 del Acuerdo 2 de 2011.

Cuadro 1. Definición de los códigos para las categorías de análisis definidas para el análisis. 


\begin{tabular}{ll} 
CÓDIGO & PR (Producción de contenidos infantiles) \\
\hline DEF INICIÓN & Artículos que regulen la cantidad en horas u otra medida, de contenidos infantiles que deben ser \\
COMPLETA & emitidos por los operadores de televisión. \\
EJEMPLO & Acuerdo 02 de 2011 \\
& $\begin{array}{l}\text { Artículo 33. Obligaciones de programación. Cada operador de televisión abierta nacional, } \\
\text { regional y local con ánimo de lucro deberá cumplir las siguientes obligaciones de } \\
\text { programación: }\end{array}$ \\
& Programación infantil \\
& Cada operador de televisión abierta deberá radiodifundir un mínimo de horas trimestrales de \\
& programación infantil, teniendo en cuenta la definición consagrada en el artículo 25 del \\
& presente Acuerdo, en el horario comprendido entre las 07:00 y las 21:30 horas, de la siguiente \\
manera: ... \\
CÓDIGO & PB (Publicidad emitida en la franja infantil) \\
DEF INICIÓN & Artículos que regulan los contenidos publicitarios que se pueden incluir en la franja infantil. \\
COMPLETA & \\
EJEMPLO & Acuerdo 04 de 2007 \\
& Artículo 6. Pertinencia de la pub licidad en las franjas horarias. La publicidad deberá responder \\
& según su contenido y tratamiento a las franjas de audiencia en que se transmita. No se podrán \\
transmitir en horario infantil o familiar, anuncios comerciales o promociones de producciones \\
cinematográficas o de programas de tele visión clasificados para mayores de edad o cuya \\
temática sea ap ta sólo para adultos.
\end{tabular}

Cuadro 1. Definición de los códigos para las categorías de análisis definidas para el análisis. (continuación)

de manera expresa la obligatoriedad de protección al cumplimiento de los derechos de los niños y además presentaba un término de seis meses para que la CNTV expidiera la reglamentación para tal efecto.

La CNTV comienza con su funcionamiento en 1996 y el primer documento normativo que relaciona el público infantil, es el acuerdo 007 de noviembre del mismo año, por el cual se dictan normas para la operación de las Cadenas Comerciales de Televisión en los niveles de cubrimiento nacional y zonal. Este acuerdo que fuera derogado por el acuerdo 010 de 1997, resulta de vital importancia, porque define el énfasis de la normatividad emanada desde la CNTV durante los siguientes años.

En la Tabla 1 se presenta la matriz diseñada con los códigos de las categorías antes expuestas, en la cual se vaciaron los artículos de cada Acuerdo, según su correspondencia. De esta manera se completa el enfoque mixto que utilizando dos fases a saber cuantitativa y cualitativa, entrega los resultados del análisis documental aplicado.

En el Gráfico 1, es evidente el énfasis puesto en la regulación de aspectos relacionados con el tratamiento audiovisual y el contenido en la franja infantil:

De los 61 artículos, el 49\% (30) exponen normas frente al contenido y el tratamiento audiovisual del mismo.

El 20\% (11) se concentran en determinar la franja horaria y/o la clasificación de la programación según el horario de emisión, y en el mismo porcentaje, (11) hablan del tratamiento de la publicidad.

El 10\% (6) exponen la necesidad de advertir sobre el contenido de acuerdo al público.

- El 3\% (2) hablan de la obligación en relación con el número de horas de producción de programas infantiles.

El 2\% (1) es expedido especialmente para garantizar el acceso de las personas sordas e hipoacúsicas al servicio público de televisión. 


\begin{tabular}{|c|c|c|}
\hline CÓDIGO & ACUERDO & ARTÍCULOS \\
\hline $\begin{array}{l}\text { FHPG } \\
\text { (Franjas horarias y } \\
\text { programación) }\end{array}$ & $\begin{array}{l}07 \text { de } 1996 \\
\text { Derogado por el } \\
\text { Acuerdo } 010 \text { de } \\
1997 \\
010 \text { de } 1997 \\
017 \text { de } 1997 \\
03 \text { de } 2010 \\
02 \text { de } 2011 \\
\text { Modificado por el } \\
\text { Acuerdo } 003 \text { de } \\
2011 \text {. }\end{array}$ & $\begin{array}{l}3,16 \\
\\
3,15 \\
2 \\
19,20,29 \\
24,25,26\end{array}$ \\
\hline $\begin{array}{l}\text { AHER } \\
\text { (Advertencia edad mínima / hora } \\
\text { de recepción) }\end{array}$ & $\begin{array}{l}07 \text { de } 1996 \\
010 \text { de } 1997 \\
01 \text { de } 2006 \\
04 \text { de } 2007 \\
02 \text { de } 2011\end{array}$ & $\begin{array}{l}16 \\
15,59 \\
8 \\
2,4 \\
34\end{array}$ \\
\hline $\begin{array}{l}\text { CTA } \\
\text { (contenido y tratamiento } \\
\text { audiovisual) }\end{array}$ & $\begin{array}{l}07 \text { de } 1996 \\
010 \text { de } 1997 \\
017 \text { de } 1997 \\
01 \text { de } 2006 \\
\text { 03 de } 2010 \\
\text { Modificado } \\
\text { parcialmente por el } \\
002 \text { de } 2011 \\
\end{array}$ & $\begin{array}{l}16,29,30,60 \\
15,29,59 \\
4,7,8,9,10,13,14,16,17,1 \\
8,29 \\
4,5 \\
22,24,26\end{array}$ \\
\hline & $\begin{array}{l}02 \text { de } 2011 \\
03 \text { de } 2011\end{array}$ & $\begin{array}{l}27,28,29,31 \\
2,3,4\end{array}$ \\
\hline $\begin{array}{l}\text { PR } \\
\text { (Producción de contenidos } \\
\text { infantiles) }\end{array}$ & $\begin{array}{l}03 \text { de } 2010 \\
02 \text { de } 2011\end{array}$ & $\frac{6}{33}$ \\
\hline $\begin{array}{l}\mathbf{A C C} \\
\text { (Acceso a los contenidos para el } \\
\text { público infantil) }\end{array}$ & 01 de 2012 & 11 \\
\hline $\begin{array}{l}\text { PB } \\
\text { (Publicidad emitida en la franja } \\
\text { infantil) }\end{array}$ & $\begin{array}{l}07 \text { de } 1996 \\
010 \text { de } 1997 \\
017 \text { de } 1997 \\
04 \text { de } 2005 \\
01 \text { de } 2006 \\
04 \text { de } 2007\end{array}$ & $\begin{array}{l}29 \\
29 \\
23,24,29 \\
4 \\
4,5 \\
6\end{array}$ \\
\hline
\end{tabular}

Tabla 1. Análisis de aspectos normativizados en los acuerdos emitidos por la Comisión Nacional de Televisión CNTV, entre 1996 y 2012. Fuente: Elaboración propia.

Al considerar los aspectos reglamentados tratados en el número total de acuerdos, con el fin de determinar el aspecto más relevante en el periodo de tiempo analizado, se exponen los resultados en el Gráfico 2:
- $\quad$ El 70\% (7) de los acuerdos incluyen el aspecto de Contenido y tratamiento audiovisual del mismo.

El 60\% (6) consideran la forma como se debe incluir la publicidad en las franjas y programas para el público infantil. 


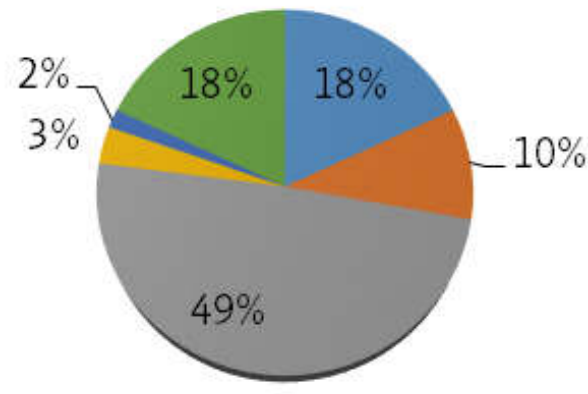

Franja

Advertencia

Contenido y Tratamiento

- Producción

Gráfico 1. Análisis del número de artículos relacionados por aspecto normativizado, con relación al número de acuerdos emitidos entre 1996 y 2012, por la Comisión Nacional de Televisión. Fuente: elaboración propia.

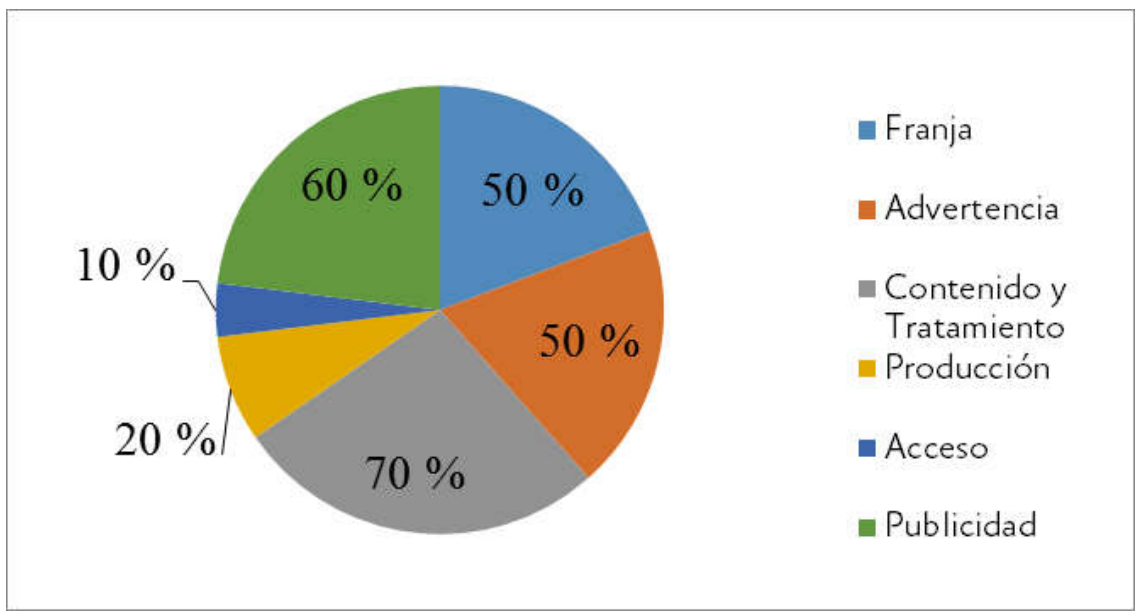

Gráfico 2. Aspectos reglamentados con relación al número total de Acuerdos. Fuente: elaboración propia. 


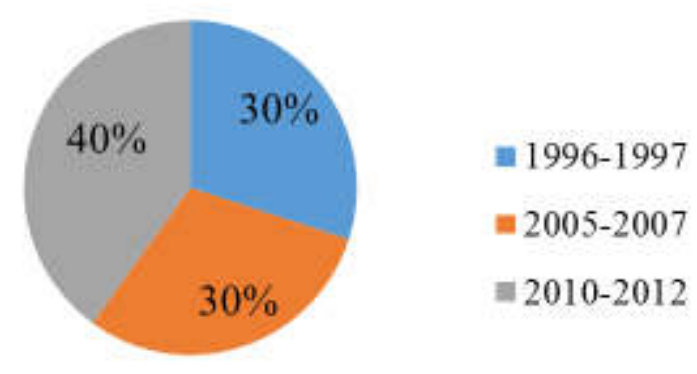

Gráfico3. Periodicidad expedición de Acuerdos. Fuente: elaboración propia.

- $\quad$ El 50\% (5) se interesaron en determinar la franja horaria y/o clasificar la programación de acuerdo con el horario y el público.

El 50\% (5) incluyen artículos que reglamentan la necesidad de advertir sobre el contenido y su adecuación al público.

El 20\% (2) determinan el número de horas de producción de televisión infantil.

- $\quad$ El 10\% (1) es dedicado a garantizar el acceso al servicio público de televisión.

El gráfico 3, presenta el análisis de la periodicidad con que se expidieron los acuerdos, encontrando que entre 1996 y 1997 , se expidieron el 30\% (3) de ellos; entre el 2005 y el 2007, otro porcentaje igual, y entre el 2010 y el 2012, el 40\% (4) restantes.

\section{Discusión.}

En el año 2007, Muñoz, director del proyecto de investigación criterios básicos para una política de televisión para niños y jóvenes en Colombia afirma que:

Aunque han existido programas de televisión para niños y -en menor cantidad- para jóvenes, y regulación normativa respecto a los contenidos de las franjas infantiles, familiares y adultas, dicha programación se reduce a ciertos tópicos 'divertidos', a una oferta mayoritariamente extranjera, incumpliendo habitualmente la ley e impidiendo la participación activa de niños y jóvenes en su producción por cuanto continúan siendo realizados por adultos, aunque el Plan de Desarrollo de la Televisión (2004-07) haya planteado la creación de mecanismos para garantizar el acceso de poblaciones especiales (niños y jóvenes, entre otras) mediante la producción propia (p. 237).

Este panorama en el año 2014, no se modifica en la medida en que a pesar de que es evidente la preocupación frente al contenido y el tratamiento audiovisual del mismo con relación al público infantil, concentrando el mayor número de artículos (32) al estar presente en casi la totalidad de los Acuerdos (8), lo que resulta favorable en la medida en que estamos de acuerdo con Sánchez-Carrero \& Mendiz-Rojas (2013), quienes afirman que «cuando observamos los 
contenidos de los medios que están dirigidos a ellos, hemos de pensar que constituyen el segmento más sensible del conjunto de los espectadores tanto en el caso de la TV tradicional y más aún en el caso de los cibernautas frente a la TV online» (p. 61). Sin embargo, la televisión infantil sigue reclamando contenidos que representen la identidad, diversidad y representación de las infancias que conviven en el país.

Desde la producción, podemos destacar que el número de horas de producción se incrementa para el caso de los operadores de televisión abierta de cubrimiento nacional porque mientras que el acuerdo 010 de 1997 fijaba ocho horas semanales, para un total de cuatrocientas diez y seis anuales, el Acuerdo 002 de 2011, fija ciento ocho trimestrales para cuatrocientos treinta y dos anuales. Sin embargo, los operadores de televisión abierta de cubrimiento regional y local, disminuyen su obligación a trescientas veinte anuales.

Por otro lado la producción propia como una manera de incentivar la inclusión de las audiencias, el acuerdo 002 del 2011, elimina el parágrafo del artículo 28, del acuerdo 003 del 2010, que fijaba el número de horas emitidas en la programación infantil como 108 horas trimestrales, de las cuales el $70 \%$ serán de origen nacional, dejando la decisión en manos del operador y/o concesionario, con la tradición imperante de comprar productos extranjeros de menor valor, sin velar por las condiciones de calidad y representatividad de la niñez colombiana. Además representadas en la programación de franjas contenedoras, que como lo afirman Alonso, Matilla y Vázquez (citados por Digón, 2008, p. 66-67) «son programas baratos que, aunque suelen nutrirse principalmente por series importadas, dan a la cadena la imagen de promover la programación infantil de producción propia».

De forma paralela, diferentes entidades dentro de las que se encuentran la CNTV, la actual ANTV, y el Ministerio de la Cultura, desde hace un poco más de diez años, han fortalecido el espacio de apoyos para la producción de contenidos audiovisuales para público infantil.

Se destacan los periodos de 8 años entre 1997 y el año 2005 sin expedición de nueva normatividad o adaptación de la misma, así como durante tres años entre el 2007 y el 2010.

El manejo de la publicidad y el establecimiento de las franjas de audiencia horarias, siguen en orden de importancia. Desde la ubicación en la parrilla, supone una mayor libertad de programar de manera racional y consciente la programación infantil de acuerdo con los ritmos reales de la audiencia. Sin embargo, esto queda bajo la decisión del canal, que ha evidenciado a través del tiempo, no estar interesado en realizar investigaciones para determinar los mejores horarios para emitir sus contenidos. Sus decisiones, especialmente los operadores o concesionarios privados, obedecen a las reglas del mercado que no siempre van con de la responsabilidad frente a las necesidades reales de la audiencia «la desregulación de este sector ha conllevado la imposición de un modelo comercial tanto en la televisión privada como en las cadenas públicas» (Digón, 2008, p. 66).

Un panorama que está lejos del planteamiento de las expectativas educativas de la audiencia frente a la televisión que debería, en palabras de Fuenzalida (2010, p. 23) «asumir la función de comunicar a favor de las audiencias, contribuyendo a la mejoría de la calidad de la política regional con una indispensable comunicación política 
renovada». En un escenario que gracias a la convergencia digital «en la actualidad, no solamente hay un mayor equipamiento televisivo en los hogares, sino que los jóvenes tienen un acceso directo y personal a los medios de comunicación» (Medrano \& Palacios, 2008, p. 6), situación que genera unas audiencias más comunicadas, expuestas y con poder de decisión, que demandan nuevas competencias del sector involucrado en la producción de contenidos audiovisuales (Sandoval \& Aguaded, 2012; García-Ruíz, Duarte \& Guerra, 2014).

Reconociendo el potencial formativo de la televisión para la infancia (Cebrián \& Solano, 2008; Rincón, 2011; Sandoval, 2010), resultaría necesario además de concentrarse en la normativa de los aspectos contenidos hasta el momento en los acuerdos, trazar estrategias efectivas para una mayor producción nacional, con criterios de calidad para nuestros niños y niñas.

\section{Referencias bibliográficas.}

«Acuerdo 010/1997, de 17 de enero, Junta Directiva de la Comisión Nacional de Televisión» Recuperado de http:// www.antv.gov.co/sites/default/files/ acuerdo_010_0.pdf (2 de diciembre de 20012). «Acuerdo 003/2010, de 6 de mayo, Junta Directiva de la Comisión Nacional de Televisión » Diario Oficial 47702 (6 de mayo de 2010).

«Acuerdo 002/2011, de 30 de junio, Junta Directiva de la Comisión Nacional de Televisión » Diario Oficial 48116 (30 de junio de 2011).

Cáceres, P. (2003). Análisis cualitativo de contenido: una alternativa metodológicamente alcanzable. Psico-perspectivas, V.II, 53-82.
Cebrián, M. \& Solano, N (2008). Evaluación de material videográfico de apoyo al aula de primaria. Pixel-Bit. Revista de Medios y Educación, 33, 43-58.

Constitución Política de Colombia (1991). Recuperado de http://goo.gl/RkimDZ.

«Decreto 3363/1954, de 30 de noviembre, Presidente de la República» Diario Oficial (10 de diciembre de 1954).

«Decreto 088/1976, de 22 de enero, Presidente de la República» Diario Oficial, 34495 (23 de febrero de 1976).

«Decreto 2737/1989, de 27 de noviembre, Presidente de la República» Diario Oficial, CXXVI, 39080 (27 de noviembre de 1989), págs. 5-69.

Digón, P. (2008). Programación infantil y TV sensacionalista: entretener, desinformar, deseducar. Comunicar, 31, 65-76. doi: org/ 10.3916/c31-2008-01-008.

Documento Conpes. Departamento Nacional de Planeación DPN-2787. (1995). Ministerio de Salud-ICBF-UDS-PAFI. Recuperado de http://goo.gl/XJaKeF.

Documento Conpes Social 109 (2007). Consejo Nacional de Política Económica Social. República de Colombia. Departamento Nacional de Planeación. Política Primera Pública Nacional de Primera Infancia. Ministerio de la Protección Social; Ministerio de Educación Nacional; Instituto Colombiano de Bienestar Familiar; DNP-DDS-SS.

Fuenzalida, V. (2000). La televisión pública en América Latina. Santiago de Chile: Fondo de Cultura Económica.

Fuenzalida, V. (2010). Resignificar la educación televisiva: desde la escuela a la vida cotidiana. Comunicar, 36, 15-24. doi.: org/10.3916/C36-2011-02-01.

García-Ruíz, R., Duarte, A. \& Guerra, S. (2014). Propuesta de un instrumento de evaluación para medir el grado de competencia 
mediática en la etapa de educación infantil. Píxel-Bit. Revista de Medios y Educación, 44, 81-96. doi: http://dx.doi.org/10.12795/ pixelbit.2014.i44.06.

Instituto Colombiano de Bienestar Familiar (2006). Colombia por la primera infancia. Política pública por los niños y niñas, desde la gestación hasta los 6 años. Programa de Apoyo para la Construcción de la Política de Primera Infancia.

«Ley $75 / 1968$, de 30 de diciembre, Congreso de Colombia». Recuperada de http://goo.gl/ 8L6IuT.

«Ley $27 / 1974$, de 20 de diciembre, Congreso de Colombia». Diario Oficial, N. 34.244 (28 de enero de 1975).

«Ley $42 / 1985$, de 11 de febrero, Gobierno Nacional». Diario Oficial, Año CXXI. N. 36867 (21 de febrero de 1985), pág. 706.

«Ley 14/1991, de 29 de enero, Congreso de la República». Diario Oficial, Año CXXVII. N. 39651 (30 de enero de 1991), pág. 1.

«Ley 12/1991, de 22 de enero, Congreso de Colombia». Diario Oficial, N.39640 (22 de enero de 1991).

«Ley 182/1995, de 20 de enero, Congreso de la República de Colombia». Diario Oficial, Año CXXX. N. 41681 (20 de enero de 1995), pág. 1.

«Ley 336/1996, de 20 de diciembre, Congreso de la República de Colombia». Diario Oficial, 42948 (28 de diciembre de 1996).

«Ley 361/1997, 7 de febrero, Congreso de la República de Colombia». Diario Oficial, 42978 (11 de febrero de 1997).

«Ley 982/2006, 2 de agosto, Congreso de la República de Colombia». Diario Oficial, 45995 (9 de agosto de 2006), págs. 1-4.
«Ley 1098/2006, de 8 de noviembre, Congreso de Colombia. Código de Infancia y Adolescencia». Diario Oficial, CXLII, 46446 (8 de noviembre de 2006), pág. 1 .

«Ley 1346/2009, 31 de julio, Congreso de la República de Colombia». Diario Oficial, 47427 (31 de julio de 2009).

«Ley 1507/2012, de 10 de enero, Congreso de Colombia». Diario Oficial, CXLVII, 48308 (10 de enero de 2012), pág. 2.

Medrano, M. \& Palacios, S. (2008). Los hábitos y la dieta televisiva en distintas edades: implicaciones educativas. Pixel-Bit. Revista de Medios y Educación, 31, 1-9. Recuperado de http://goo.gl/LJ1uVt.

Muñoz, G. (2007). Criterios básicos para una política de televisión para niños y jóvenes en Colombia. Revista Nómadas, 27, 236-238.

Plan Decenal de Educación 2006-2016. Recuperado de http://goo.gl/IAL3vK.

Rincón, O. (2011). Nuevas narrativas televisivas: relajar, entretener, contar, ciudadanizar, experimentar. Comunicar, 36 , 43-50. doi: 10.3916/C36-2011-02-04.

Sánchez-Carrero, J. \& Mendíz-Rojas, H. (2013). La alfabetización mediática en la televisión infantil online: programas del Canal Pakapaka. Revista Chasqui, 124, 56-62. doi: http://dx.doi.org/10.16921\%2FCha squi.2013.N124.58

Sandoval, Y. (2010). La televisión educativa como instrumento para el desarrollo en la infancia. En Mirando cómo Miramos: Una propuesta para la recepción crítica desde la Comunicación y la educación. (pp.109-137). Cali-Colombia: Editorial USC. 2010.

Sandoval, Y. \& Aguaded, J.I. (2012). Nuevas audiencias, nuevas responsabilidades. Icono14, 10 (3), 08-22. doi: 10.7195/ri14.v10i3.197. 
Vizcaíno, M. (2005). La legislación de la televisión en Colombia: Entre el Estado y el mercado. Historia Crítica, 28, 127-152.

Fecha de recepción: 17-07-2014

Fecha de evaluación: 15-10-2014

Fecha de aceptación: 04-12-2014 